\title{
Education Research - GIM
}

Annabelle Cumyn, MD, CM, MHPE, Sharon E. Card, MSc, MD, FRCPC, and Paul Gibson, MD

\author{
About the Authors \\ Annabelle Cumyn currently works as Professor in the Department of Medicine at Sherbrooke University. \\ Sharon E. Card is a General Internist in Saskatoon, SK. \\ Paul Gibson is an Associate Professor of Medicine and Obstetrics \& Gynecology at the University of Calgary. \\ Corresponding Author annabelle.cumyn@USherbrooke.ca \\ Submitted: October 8, 2018. Accepted: December 20, 2018. Published: August 31, 2019. DOI: 10.22374/cjgim.v14i3.322
}

\begin{abstract}
\section{Background}

Obstetric Medicine is an area of expertise within General Internal Medicine (GIM) in Canada. Essential content for clinical rotations for GIM residents was identified by subject-matter experts ( $\mathrm{N}=204$ items). However, this work did not address the perspective of curriculum stakeholders.
\end{abstract}

\section{Methods}

Members of the Canadian GIM Specialty Committee (GIMSC) were surveyed to obtain their perspective on essential content that GIM residents should acquire in Obstetric Medicine.

\section{Results}

GIMSC members $(\mathrm{N}=14)$ selected "core content" which reduced the initial content blueprint by $72 \%$. Some sections of the blueprint were left largely unchanged (e.g., hypertensive disorders of pregnancy), whereas others were removed entirely (e.g., transplant medicine).

\section{Interpretation}

GIMSC were more selective than Canadian Obstetric Internists in choosing the essential content for GIM residents, with a moderate overall agreement of 78\% (kappa coefficient of 0.53). Comparison of perspectives and content mapping may provide useful validity evidence for further work.

\section{RÉSUMÉ}

\section{Contexte général}

La médecine obstétricale est un domaine d'expertise en médecine interne générale (MGI) au Canada. Le contenu essentiel des rotations cliniques pour les résidents en GIM a été identifié par les experts en la matière ( $\mathrm{N}=204$ items). Cependant, ce travail n'a pas pris en compte le point de vue des parties prenantes du curriculum.

\section{Méthodes}

Les membres du Comité canadien de spécialité en GIM (CTSG) ont été sondés afin d’obtenir leur point de vue sur le contenu essentiel que les résidents en GIM devraient acquérir en médecine obstétrique.

\section{Résultats}

Les membres de l'ASGDC ( $\mathrm{N}=14)$ ont choisi le " contenu de base ", ce qui a réduit le plan de contenu initial de $72 \%$. Certaines sections du plan directeur sont demeurées en grande partie 
inchangées (p. ex., troubles hypertensifs de la grossesse), tandis que d'autres ont été entièrement supprimées (p. ex., médecine de transplantation).

\section{Interprétation}

L'ASGDC a été plus sélective que les internistes obstétriciens canadiens dans le choix du contenu essentiel pour les résidents de l'ASG, avec un accord global modéré de 78 \% (coefficient kappa de 0,53). La comparaison des points de vue et la cartographie du contenu peuvent fournir des preuves de validité utiles pour la poursuite des travaux.

Keywords: Obstetric Medicine, curriculum development, validity evidence, competencies and skills, pregnancy, General Internal Medicine

Obstetric Medicine $(\mathrm{OM})$ is a growing discipline that provides care for women with medical conditions entering pregnancy or women who develop medical complications during gestation and/or the early postpartum period. ${ }^{1}$ General Internal Medicine (GIM), like other Canadian residency programs, is adapting to societal needs to ensure that new specialists have achieved minimal competency in many clinical situations - including the assessment and management of medical conditions around pregnancy. Royal College of Physician and Surgeons (RCPSC) accredited GIM residency programs (PGY 4 and 5 ) are required to include clinical rotations in $\mathrm{OM}$ to ensure that practicing General Internists have the necessary baseline competency to evaluate and manage this special population. A survey of Canadian internists identified different levels of mastery that should be required of a GIM training program to facilitate the transition to practice. ${ }^{2 "} \mathrm{OM}$ was felt to be an area in which a level of proficiency (rather than expertise) should be attained. Previous work has already described a gap between the "importance rating" of an area of practice and the "preparation rating" after residency training in GIM. ${ }^{3}$ In that Canadian survey, the field of 'medical problems of pregnancy' was identified as an area with one of the highest needs for training improvement in order to support the achievement of competency.

Competency appears to be based on the acquisition of essential content, followed by the mobilization of knowledge and deliberation on practice. ${ }^{4-8}$ The Royal College of Physicians and Surgeons of Canada (RCPSC) has committed to competency-based medical education (CBME) and is transforming post-graduate education within a unique model called Competence By Design (CBD). ${ }^{9-12}$ Concurrently, the Canadian Consensus for a Curriculum in OM (CanCOM) research group was formed in 2010 and includes a majority of Canadian Obstetric Internists (current membership of $\mathrm{N}=49$ physicians). This group of subject-matter experts validated a content blueprint of $\mathrm{N}=497$ items divided into 21 sections to characterize the emerging field of $\mathrm{OM}$ as a whole. ${ }^{13}$ More recently, $\mathrm{N}=22$ members of the research group completed a survey based on the initial blueprint. The survey asked these Obstetric Medicine specialists (OMS) to review the blueprint of $\mathrm{N}=497$ items and select the essential content that should be the basis of clinical exposure during OM rotations for PGY 4-5 GIM residents in Canada. ${ }^{14}$

In this study, we repeat the survey with members of the Canadian RCPSC GIMSC to obtain their perspective on essential content for OM rotations. A second objective is to compare the GIMSC and OMS perspectives. This comparison will provide a description of the content for which there is an agreement to include as essential or exclude as well as areas with discordant opinions. This map may be useful for the development of pertinent, valid pedagogical approaches for the teaching of OM during GIM residency programs. Ultimately, the aim is to deliver competent GIM specialists to meet the needs of this unique patient population.

\section{Methods}

The GIM SC is mandated by the RCPSC to define their disciplinespecific national standards, based on the educational framework of the RCPSC. At the time of the study, the GIMSC consisted of 25 members, including 14 GIM Program Directors and 9 appointed representatives (regional, community, examination and national specialty society) that meet on a regular basis.

We asked members of the Canadian GIMSC to review the blueprint of $\mathrm{N}=497$ items - divided into 21 sections - and to select the essential content that they would like post-graduate years 4-5 residents in GIM to be exposed to during their rotation(s) in OM. The research instrument used was identical to the one completed by the OMS and was based on prior work developing and validating a content blueprint for Obstetric Medicine by Canadian Obstetric Medicine subject-matter experts. ${ }^{13,15}$ This study aimed to compare the essential content selected by the 
OMS and members of the GIMSC in charge of establishing national competency standards.

\section{Statistical Analysis}

Descriptive statistics were used to compare both sets of results. A cut-off of $80 \%$ was set a priori as a measurement of substantial agreement. A simple Kappa coefficient was used as a measure of the overall agreement. McNemar's test was performed as a test of marginal homogeneity. The statistical significance was set at a $p$ value of 0.05 or lower.

\section{Ethics Approval}

This study was approved by the research ethics board in Education and Social Sciences of the Université de Sherbrooke, Quebec, Canada.

\section{Results}

Fourteen (14) of the twenty-five (25) members of the GIMSC were present at the time of a planned face-to-face meeting. All available members agreed to participate in the study and completed the research instrument. Of the 497 items in the initial CanCOM content blueprint, 132 items were selected as 'core content' by at least 11/14 of members (a percent agreement of at least $78.6 \%$ ). This would result in a $73 \%$ reduction of the initial content blueprint (see Figure 1).

Among the 22 OMS who performed the same task: 204 out of 487 items were selected by at least 18/22 respondents (a percent agreement of at least $81.8 \%$ ). ${ }^{14}$ This resulted in a $58 \%$ reduction of the content blueprint (see Figure 1).

The overall agreement between both groups regarding essential content was moderate: both groups agreed to include or exclude 380 out of the 487 items, a level of agreement of $78 \%$ with a simple kappa coefficient of 0.53 (0.46-0.61). Conversely, there were discordant ratings for $\mathrm{N}=107$ items (see Figure 2).

When in disagreement, OMS were significantly more likely to include items than the GIMSC members $(\mathrm{p}<0.001)$.

Within the 21 sections of the content blueprint, six exhibited low levels of agreement (as detailed in Table 1).

There was a non-significant trend towards a lower level of agreement for content blueprint sections with a lower number of items (McNemar's $\mathrm{p}=0.11)$. The remaining 15 sections of the content blueprint displayed higher levels of agreement (whether to include or exclude an item) ranging from 70 to $100 \%$ (Table 2).

Of interest, regarding the eight sections with an agreement level inferior or equal to $85 \%$, the OMS group indicated a persistent preference to include items that the GIMSC would not have included (see Table 2).

The comparison between the perspectives the two groups can be mapped (Figure 3).

Each spoke represents one of the 21 sections of the initial curriculum blueprint. ${ }^{13}$ The smaller blue map shows the essential content as selected by the GIMSC whereas the larger orange map displays the content selected for inclusion by the OMS. It is apparent that some sections (e.g., transplant medicine and

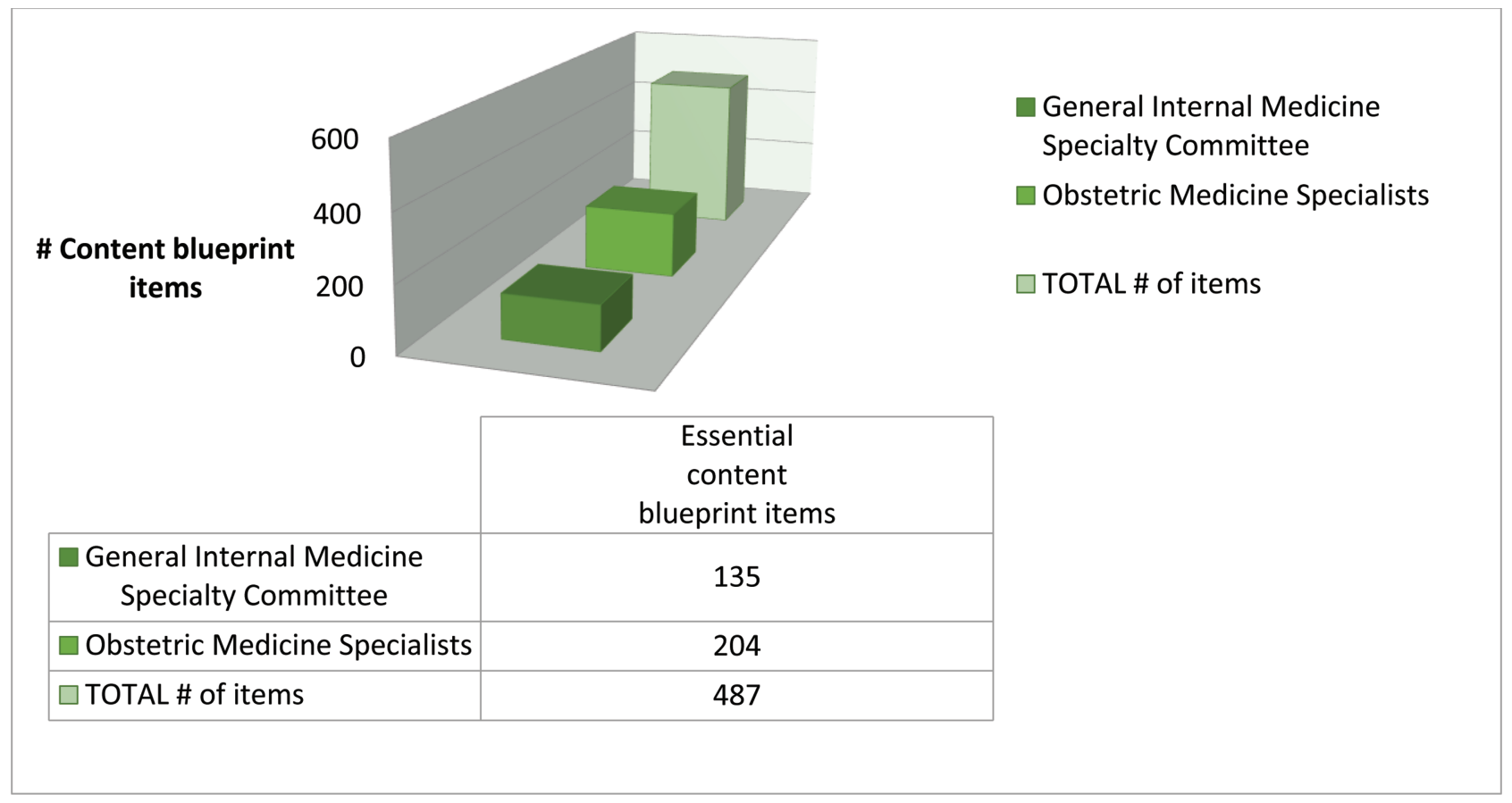

Figure 1. Selection of essential content items by the two groups of raters. 


\section{Description of levels of agreement}

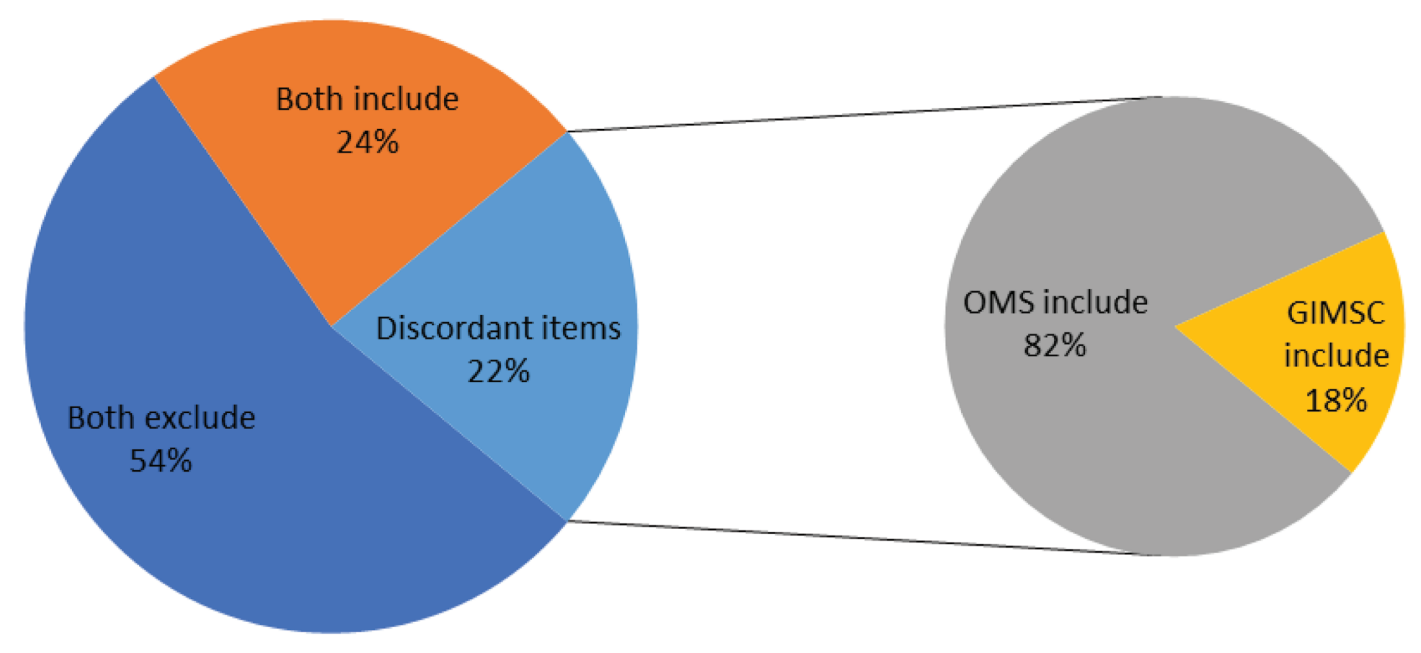

Figure 2. Description of levels of agreement between the groups of raters.

Table 1. Sections of the Cancom Blueprint** With Low Levels of Agreement

\begin{tabular}{|c|c|c|}
\hline SECTION NAME & $\%$ AGREEMENT* & COMMENTS \\
\hline 12.0 Respirology & $67 \%$ & Items relating to Asthma were largely excluded by GIMSC and largely included by OMS \\
\hline 2.0 Physiology of pregnancy & $67 \%$ & GIMSC included 5/12 items whereas OMS included 9/12 items \\
\hline $\begin{array}{l}5.0 \text { Acute care and maternal } \\
\text { resuscitation }\end{array}$ & $64 \%$ & $\begin{array}{l}\text { GIMSC included } 7 / 14 \text { items whereas OMS included } 4 / 14 \text { items favouring items related to } \\
\text { resuscitation }\end{array}$ \\
\hline $\begin{array}{l}\text { 3.0 Pharmacology of pregnancy } \\
\text { and lactation }\end{array}$ & $50 \%$ & GIMSC included 1/8 items whereas OMS included $4 / 8$ items \\
\hline 13.0 Nephrology & $41 \%$ & Certain items excluded by GIMSC were selected by $86 \%$ and greater by OMS \\
\hline 1.0 CanMEDS roles & $38 \%$ & GIMSC included 18/35 items whereas the OMS included 8/35 \\
\hline
\end{tabular}

${ }^{*}$ Agreement in this article refers to the \% of items included or excluded by both groups

** The original CanCOM content blueprint can be found at http://gemoq.ca/welcome-to-the-gemoq/cancom-research-group/

neoplastic disorders) disappear from the map as they contain no essential items, whereas other sections (e.g., hypertensive disorders) remain largely untouched with both maps overlapping (i.e., $100 \%$ agreement).

\section{Interpretation}

Members of the GIM Specialty Training Committee reduced the initial OM content blueprint to essential content for GIM PGY4-5 residents by removing nearly three-quarters of the original items. This reduction was significantly greater than the contraction proposed by OM subject-matter experts. ${ }^{14}$ The overall level of agreement between both groups regarding which items to select or exclude was moderate. ${ }^{16}$ Some sections, however, demonstrated very high levels of agreement - and these were generally core areas of OM. The final output is a map of $\mathrm{N}=116$ content items that were judged to be "essential" by both groups.

It is interesting to contemplate why subject-matter experts (OMS) would be more inclusive and thus less likely to reduce the initial, comprehensive blueprint of an emerging field to a short list of essential content. One possible explanation is that 
Table 2. Sections of the Cancom Blueprint ** With High Levels of Agreement (In Decreasing Order)

\begin{tabular}{|c|c|c|}
\hline SECTION NAME & $\%$ AGREEMENT* & COMMENTS \\
\hline $\begin{array}{l}\text { 4.0 Diagnostic and therapeutic } \\
\text { radiation }\end{array}$ & $100 \%$ & included 2/4 items \\
\hline $\begin{array}{l}6.0 \text { Surgical and anesthetic } \\
\text { considerations }\end{array}$ & $100 \%$ & 6/7 items excluded \\
\hline 14.0 Transplant medicine & $100 \%$ & all 6 items excluded \\
\hline 19.0 Neoplastic disorders & $100 \%$ & all 6 items excluded \\
\hline $\begin{array}{l}7.0 \text { Relevant obstetric and } \\
\text { gynecologic conditions }\end{array}$ & $95 \%$ & 20/21 items excluded \\
\hline 21.0 Psychiatric illness & $95 \%$ & 20/22 items excluded \\
\hline 8.0 Hypertensive disorders & $94 \%$ & $31 / 34$ items included by both \\
\hline 10.0 Endocrinology & $85 \%$ & $\begin{array}{l}\text { Agreement* on 63/74 items; OMS would have included another } 11 \text { items related to } \\
\text { hypothyroidism and metabolic syndrome }\end{array}$ \\
\hline 11.0 Hematology & $83 \%$ & $\begin{array}{l}\text { Agreement on 30/36 items; OMS would have included another } 6 \text { items related to immune } \\
\text { thrombocytopenic purpura, thrombophilias, and anticoagulation }\end{array}$ \\
\hline 18.0 Immunologic diseases & $81 \%$ & $\begin{array}{l}\text { Agreement on } 21 / 26 \text { items; OMS would have included another } 5 \text { items related to systemic } \\
\text { lupus erythematosus }\end{array}$ \\
\hline 9.0 Cardiology & $79 \%$ & $\begin{array}{l}\text { Agreement on 22/28 items; OMS would have included another } 6 \text { items related to } \\
\text { congenital heart disease and peripartum cardiomyopathy }\end{array}$ \\
\hline 16.0 Neurology & $79 \%$ & $\begin{array}{l}\text { Agreement on 38/48 items; OMS would have included another } 9 \text { items related to } \\
\text { headaches and seizure disorders }\end{array}$ \\
\hline 15.0 Gastroenterology & $75 \%$ & $\begin{array}{l}\text { Agreement on 34/45 items; OMS would have included another } 11 \text { items related to } \\
\text { dyspepsia, acute fatty liver of pregnancy, inflammatory bowel disease, and obstetric } \\
\text { cholestasis }\end{array}$ \\
\hline 20.0 Dermatology & $75 \%$ & $\begin{array}{l}\text { Agreement on } 6 / 8 \text { items; OMS would have included another } 2 \text { items related to pruritus in } \\
\text { pregnancy }\end{array}$ \\
\hline 17.0 Infectious disease & $70 \%$ & $\begin{array}{l}\text { Agreement on } 21 / 30 \text { items; OMS would have included another } 8 \text { items related to sepsis, } \\
\text { pneumonia, and HIV }\end{array}$ \\
\hline
\end{tabular}

*Agreement in this article refers to the $\%$ of items included or excluded by both groups

** The original CanCOM content blueprint can be found at http://gemoq.ca/welcome-to-the-gemog/cancom-research-group/

the OMS may find it more difficult to label any content as nonessential - as the conditions included in the original curriculum content blueprint are all present in their clinical practice. It is also possible that GIMSC members had the Competence-by-Design model in mind during the adjudication process, and were thus more able to focus on selecting truly essential items. However, both groups of raters had difficulty in excluding items - as every item of the 487 items was selected by at least one and usually
2 or more individual raters. Regardless, this study provides pertinent information - both by highlighting the $78 \%$ of the content for which there was substantial agreement, as well as by identifying the areas that require further consideration due to the discordant opinions. For instance, acute care and maternal resuscitation was a section with a lower overall agreement of $67 \%$. Are the OMS correct in their assessment that resuscitation should be an essential part of the PGY4-5 GIM training? After 


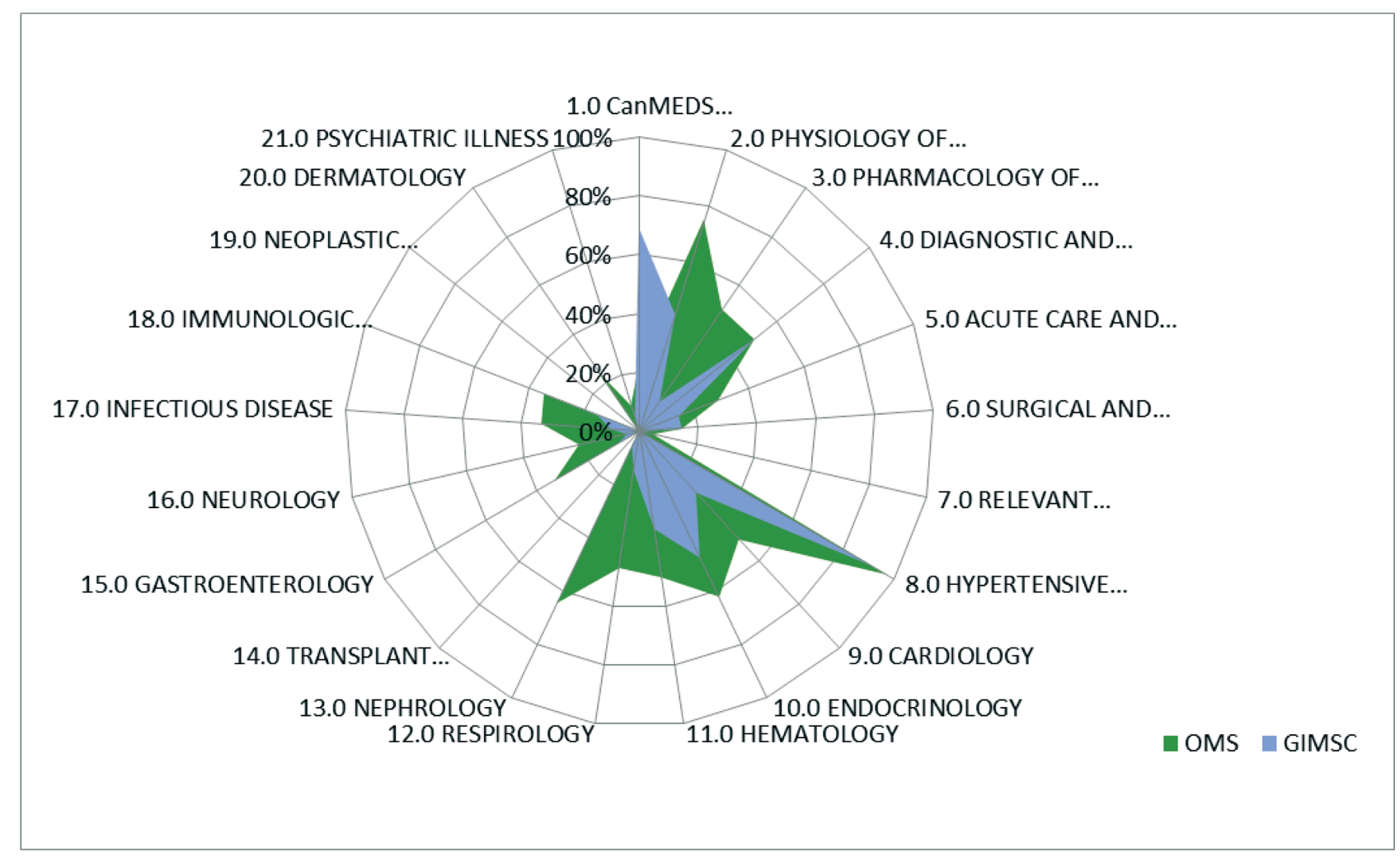

Figure 3. Mapping of the reduced (essential) content blueprint according to both groups.

all, resuscitation of the pregnant patient requires adjustments to BCLS and ACLS protocols that many general practitioners may not be aware of (such as manual displacement of the uterus, emergency perimortem Caesarean section within 4 minutes after cardiac arrest, etc). Of course, such events are rare but, if this content is judged essential to the development of competency, then alternate pedagogical strategies such as simulation may need to be organized. This highlights the importance of developing curricula from different viewpoints to ensure that the needs of patients are well served by ensuring that rare but critical events are included in the education of our graduates. This is particularly true for a generalist discipline such as GIM where graduates frequently practice with limited subspecialty back-up.

Another way of reading this data is to see OM content as a three-tiered pyramid of content expertise (Figure 4).

In this model, one can separate the highly specialized content that an OM content specialist would acquire within extra fellowship-level training, from the area of expertise of a GIM specialist with an interest in the care of women with complex medical problems, from the more focused competency of every practicing GIM specialist. If confirmed by further work, this separation of the content may also set standards with regards to when a patient requires transfer to very specialized care, generally in tertiary and quaternary-level health care facilities.

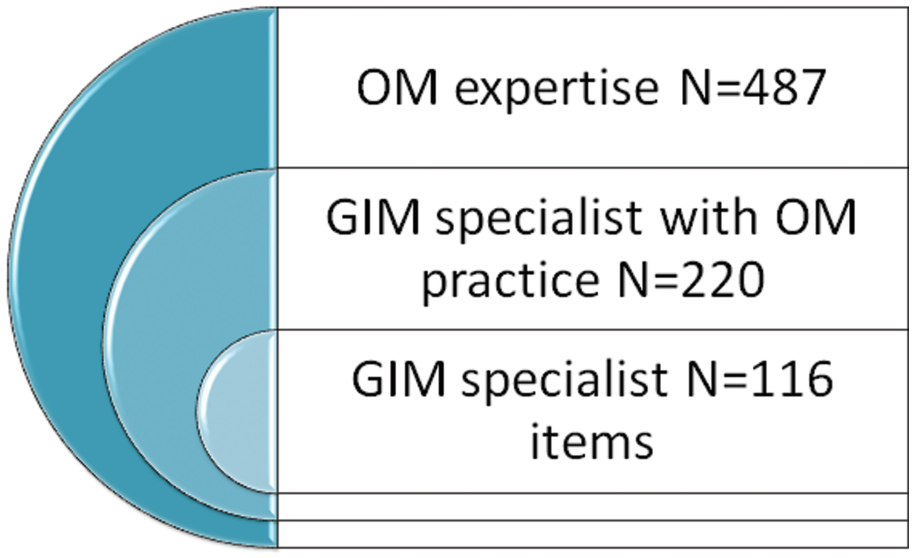

Figure 4. Proposed model of a three-level expertise in OM and the number of corresponding content items.

Another important question is how this content blueprint fits within the transition to CBME. Indeed, proponents of competency-based curricula remind us that when curricula rely heavily on lists of content, learning is not well integrated across the curriculum. ${ }^{9}$ This work is not intended as a step back towards a focus on process rather than outcomes. Rather, we consider that a prerequisite to the development of milestones and entrustable professional activities, as described in the 
Pediatrics Milestones project, ${ }^{17}$ is a solid understanding of the content domain. In addition, content blueprints have a role to play in the development of assessment blueprints and to support the development of novel pedagogical approaches such as the CanCOM clinical cases. Another way in which these results may be used in the CBD transition is by supplying data to better describe learning trajectories within CBME. ${ }^{18}$ Indeed, while retaining a focus on the outcome of attaining competency, clinician-educators will need to be able to conclude with some degree of confidence that graduates have the necessary clinical exposure, knowledge, and task ability. ${ }^{11}$

\section{Limitations}

This survey includes only the opinions of 14/25 of the 2016 GIMSC members. The results cannot be applied directly to other countries as Canada is fairly unique in its approach to training GIM specialists with the extra 2 years of residency training and the CBD transition. ${ }^{19}$ However, the discipline of OM is developing across the world and therefore the concept of a baseline, essential content blueprint could be informative in other settings.

\section{Conclusion and Future Directions}

This comparison of opinions regarding essential content for an OM curriculum within GIM (PGY4-5) residency informs both by identifying areas of agreement as well as by highlighting the sections where opinions are more divergent. A substantial part of the curriculum map displays high levels of agreement, which may serve to support future work within the CBD framework such as justifying the list of common or emergent obstetrical medical presentations that can constitute the target of an entrustable professional activity. Such evidence may also serve the development of pedagogical approaches such as simulation and clinical cases or as validity evidence for assessment. ${ }^{20}$

Future work in this domain could include mixed-methodology to further explore the 107 discordant content items. Such an approach would clarify the underlying reasoning and explore the distinctive motivations between these groups with differing expertise (content expertise [OMS] versus stakeholders [GIMSC]). If deemed necessary, recourse to a Delphi methodology could lead to a further consensus within the discordant items. Alternatively, this work could be repeated in different settings (countries) or with residents from a different specialty (for example, residents specializing in Maternal-Fetal Medicine, high-risk pregnancy). Another need is addressing patients' needs wherever their location. To ensure that all Canadian patients have access to the right specialist in a timely fashion, the content could be mapped for those disorders that generalist specialists (GIM) need to be able to independently manage due to the need to manage close to patient's homes (eg emergency conditions such as resuscitation) versus conditions that require referral from rural to an urban quaternary centres. Because the complexity of pregnancy with medical concerns is increasing, regular review and adjustments of OM curricula will be important.

\section{References}

1. Nelson-Piercy C, Peek MJ, and Swiet MD. Obstetric physicians: are they needed? The workload of a medical complications in pregnancy clinic. J R Coll Physicians Lond 1995;30:150-54.

2. Card SE, Pausjenssen AM, and Ottenbreit RC. Determining specific competencies for General Internal Medicine residents (PGY 4 and PGY 5). What are they and are programs currently teaching them? A survey of practicing Canadian General Internists. BMC Res 2011;Notes 4, 480-0500-4-480.

3. Card SE, Snell L, and O'Brien B. Are Canadian General Internal Medicine training program graduates well prepared for their future careers? BMC Med Educ 2006;6:56.

4. Elstein AS, Shulman LS, and Sprafka SA. Medical problem solving an analysis of clinical reasoning. Harvard University Press; 1978.

5. Schmidt H, Norman G, and Boshuizen H. A cognitive perspective on medical expertise: theory and implications. Acad Med 1990;65:611-21.

6. Patel VL and Groen GJ. The general and specific nature of medical expertise: A critical look. Gen Theory Expert Prospects Limits 1991;93-125.

7. Patel VL, Glaser R, and Arocha JF. Cognition and expertise: acquisition of medical competence. Clin Invest Med 2000;23:256-60.

8. Norman G, Young M, and Brooks L. Non-analytical models of clinical reasoning: The role of experience. Med Educ 2007;41:1140-145.

9. Frank JR, et al. Competency-based medical education: theory to practice. Med Teach 2010;32:638-45.

10. Iobst WF, et al. Competency-based medical education in postgraduate medical education. Med Teach 2010;32:651-56.

11. Holmboe ES, et al. A call to action: the controversy of and rationale for competency-based medical education. Med Teach 2017;39:574-81.

12. Frank JR, editor. The CanMEDS 2005 physician competency framework. Better standards. Better physicians. Better care. Royal College of Physicians and Surgeons of Canada. Ottawa; 2005.

13. Cumyn A and Gibson P. Validation of a Canadian curriculum in OM. Obstet Med Med Pregnancy 2010;3:145-51.

14. Cumyn A and Gibson P. Validation of content of clinical cases in OM for a shared web-based educational tool. Obstet Med 2018.

15. Cumyn A and Harris IB. A comprehensive process of content validation of curriculum consensus guidelines for a medical specialty. Med Teach 2012;34:e566-e572.

16. Hallgren KA. Computing inter-rater reliability for observational data: an overview and tutorial. Tutor Quant Methods Psychol 2012;8:23.

17. Carraccio C. et al. Building a framework of entrustable professional activities, supported by competencies and milestones, to bridge the educational continuum. Acad Med 2017;92:324-30.

18. Gruppen L. et al. Toward a research agenda for competency-based medical education. Med Teach 2017;39:623-30.

19. Card SE, Clark HD, Elizov M, Kassam N. The Evolution of General Internal Medicine (GIM) - Google Scholar. Available at: https://scholar.google.ca/ scholar?hl=en\&as_sdt=0\%2C5\&q=The+Evolution+of+General+Internal+ Medicine+\%28GIM\%29in+Canada\%3A+International+Implication\&btnG= (Accessed: 15th September 2018)

20. Downing SM. Validity: on the meaningful interpretation of assessment data. Med Educ 2003;37:830-37. 